reality, a Richmond footballer than which no greater Richmond footballer can be conceived. Can you tell me why you maintain that there is no contradiction in supposing that there is no Richmond footballer than which no greater Richmond footballer can be conceived - no Richmond footballer with maximal unmediated football-related causal powers - even though you maintain that there is a contradiction in supposing that there is no being than which no greater being can be conceived - no being with maximal unmediated causal powers?

SOPHIS

Monash University

Clayton Campus

Wellington Road

Clayton Vic 3800, Australia graham.oppy@monash.edu

\title{
References
}

Matthews, G. and L.R. Baker. 2010. The ontological argument simplified. Analysis 70: 210-12.

Matthews, G. and L.R. Baker. 2011. Reply to Oppy's fool. Analysis 71, doi:10.1093/ analys/anr012.

Oppy, G. 2011. Objection to a simplified ontological argument. Analysis 71: 105-6.

\section{Pinocchio against the dialetheists}

\section{Peter Eldridge-SMith}

In a possible world far, far away lived a puppet named Pinocchio, who came to life like a little boy - but with such a nose for truth that it would grow if, and only if, he was telling a lie. When he grew up, having such an honest face, he entered politics; and Giuseppe, formerly a puppeteer, became his counsellor and spin doctor. Giuseppe taught Pinocchio the valid force of truth. Giuseppe advised Pinocchio never to answer media taunts about whether his nose is growing. Should Pinocchio say that his nose is growing, a contradiction would obtain (Eldridge-Smith and Eldridge-Smith 2010). Giuseppe himself lived in angst about the classically valid consequences of such a contradiction. He also warned Pinocchio to beware the dark force of 
dialetheias (true contradictions) and their logical masters, the dialetheist lords who might seek to beguile him into paraconsistency. So it was that Protagoras, under the guise of incontestably mild-mannered Euathlas, greeted Pinocchio at the possible world parliament and sought to bring him under his aegis. Now this dialetheist lord lived in the same possible world as Pinocchio, yet he did not. For Pinocchio's world was consistent in metaphysics and semantics; however, for the dialetheist lord, the world, though metaphysically consistent, was semantically inconsistent.

In his world, Pinocchio was in love with the blue fairy, Fey Hypatia, but lunatic members of an otherwise logically orthodox group abducted Hypatia, strewing her philosophy books about the streets. Protagoras, though with no prior aforethought, used this to pull Pinocchio's strings. 'Join with me', said Protagoras-Euathlas 'and we will save some sheets of Hypatia's philosophy!' 'No, never!' said noble Pinocchio, nervous that his nose grew a bit. Spying this, the dialetheist lord said 'There, the truth is written on your face!' But then Pinocchio agreed, 'My nose is growing.' And then the possible world ended. The dialetheist lord did and did not spin out of control into space, as his and Pinocchio's world became metaphysically impossible.

Dialetheists astutely dodge Explosion, the logical contagion of everything being true if a single contradiction is true. A dialetheia is contained in their semantics, and sustained by a suitably paraconsistent logic. Astute dialetheists do not believe in metaphysical contradictions, just semantic ones. For them, it is possible to be in the room and not in the room when they stand astride the door opening. This, for them, does not pose a contradiction about where they physically are, just a semantic contradiction in the extension of the predicate 'am in the room'. For, while 'am in the room' is an empirical predicate, any contradiction about where they stand is a matter of interpretation, not being in two places at once. It has been substantially demonstrated by Priest (2006) that this can be made systematic, and that such a system of paraconsistent logic is a solution to the Liar paradox. However, the Pinocchio paradox, devised by my daughter, Veronique, is a version of the Liar paradox that resists such a solution. The Pinocchio paradox turns on the truth of Pinocchio - whose nose grows if, and only if, what he is saying is not true - saying 'My nose is growing.' 'Is growing' is an empirical predicate, not a semantic one. Furthermore, it is not just a matter of interpretation whether Pinocchio's nose is and is not growing. If it is a true contradiction that Pinocchio's nose grows and does not grow, then such a world is metaphysically impossible, not merely semantically impossible. ${ }^{1}$

1 The Pinocchio paradox was devised by Veronique Eldridge-Smith in February 2001. I had her draw it up as a cartoon, which I used in some conference presentations. I thank the referee and the editor for pointing out that the Pinocchio paradox has intellectual ancestors also involving empirical predicates. These are scenarios about promises paradoxically thwarted by logic. For example, in Buridan's 17th sophism in Chapter 8 of his Sophismata, Plato promises to either let Socrates across a bridge or throw him into the 
308 I PETER ELDRIDGE-SMITH

\section{Australian National University \\ Canberra ACT 0200 \\ Australia \\ peter.eldridge-smith@anu.edu.au}

\section{References}

Eldridge-Smith, P. and V. Eldridge-Smith. 2010. The Pinocchio paradox. Analysis 70: 212-15.

Priest, G. 2006. In Contradictio: A Study of the Transconsistent, 2nd edn. Oxford: Oxford University Press.

water depending on whether his next statement is respectively true or false. Socrates, of course, says 'You are going to throw me into the water.' 